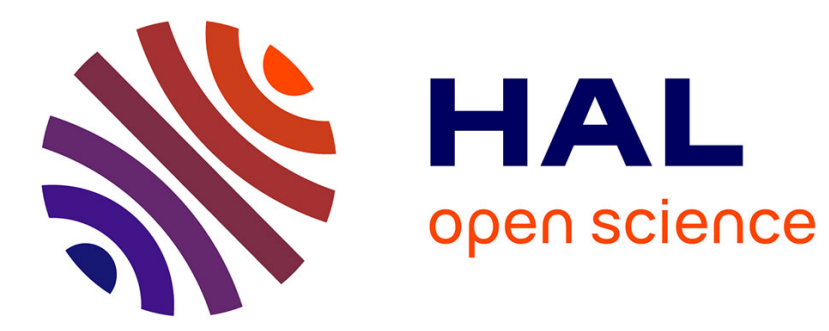

\title{
Non-destructive characterization of mechanically processed waste printed circuit boards - particle liberation analysis
}

Akira Otsuki, Luc de La Mensbruge, Andrew King, Silvia Serranti, Ludovica

Fiore, Giuseppe Bonifazi

\section{To cite this version:}

Akira Otsuki, Luc de La Mensbruge, Andrew King, Silvia Serranti, Ludovica Fiore, et al.. Nondestructive characterization of mechanically processed waste printed circuit boards - particle liberation analysis. Waste Management, 2020, 102, pp.510 - 519. 10.1016/j.wasman.2019.11.006 . hal03488899

\section{HAL Id: hal-03488899 \\ https://hal.science/hal-03488899}

Submitted on 21 Dec 2021

HAL is a multi-disciplinary open access archive for the deposit and dissemination of scientific research documents, whether they are published or not. The documents may come from teaching and research institutions in France or abroad, or from public or private research centers.
L'archive ouverte pluridisciplinaire HAL, est destinée au dépôt et à la diffusion de documents scientifiques de niveau recherche, publiés ou non, émanant des établissements d'enseignement et de recherche français ou étrangers, des laboratoires publics ou privés.

\section{(ㅇ)(1) $\$$}

Distributed under a Creative Commons Attribution - NonCommercial| 4.0 International 


\section{Non-destructive characterization of mechanically processed}

\section{waste printed circuit boards - particle liberation analysis}

3

$4 \quad$ Akira Otsuki $^{12^{*}}$, Luc De La Mensbruge ${ }^{1}$, Andrew King $^{3}$, Silvia Serranti ${ }^{4}$, Ludovica Fiore ${ }^{4}$,

$6{ }^{1}$ Ecole Nationale Supérieure de Géologie, GeoRessources UMR 7359 CNRS, University of

7 Lorraine, 2 Rue du Doyen Marcel Roubault, BP 10162, 54505 Vandoeuvre-lès-Nancy, France

$8 \quad{ }^{2}$ Waste Science \& Technology, Luleå University of Technology, SE 97187 Luleå, Sweden.

$9{ }^{3}$ Synchrotron SOLEIL, L'Orme des Merisiers Saint-Aubin, BP 4891192 Gif-sur-Yvette Cedex,

10 France

$11{ }^{4}$ Dipartimento di Ingegneria Chimica Materiali Ambiente, La sapienza - University of Roma,

12 Via Eudossiana, 1800184 Rome, Italy

13

14

*Corresponding author: akira.otsuki@univ-lorraine.fr

15

16

17

18

19

20

21

22

23

24

25 


\section{Abstract}

This work aimed to develop and propose methods for evaluating the metal degree of liberation to characterize the metal deportment/concentration and liberation/association of mechanically processed waste Printed Circuit Boards (PCBs) that hold the complex and heterogeneity structure and metal distribution/association. Waste PCBs passed through a series of mechanical processing (i.e. comminution, sieving) for the metal recovery were characterized to understand and to evaluate the metal distribution and degree of liberation of the metals in order to optimize the comminution process, avoiding excessive fine particle production. The characterizations were performed at laboratory scale, as well as utilizing large scale experimental facilities, i.e. a portable X-Ray Fluorescence (XRF), micro-XRF and Synchrotron X-Ray Tomography. The proposed methods confirmed that metal liberation was very high in the fine size fraction $(0.125$ $0.350 \mathrm{~mm})$ while many locked particles were identified in the coarse size fraction $(0.350-0.500$ $\mathrm{mm}$ ). Such results were analyzed and were discussed in order to better understand metal deportment/concentration behaviors. The advantages and disadvantages related to the different characterization approaches were identified and discussed in this paper, as well as their methodological developments in a waste PCBs' mechanical processing perspective.

\section{Keywords:}

Metal deportment/concentration; liberation; elemental analysis; micro X-ray fluorescence; synchrotron; tomography; recycling 


\section{INTRODUCTION}

Waste Electrical and Electronic Equipment (WEEE) is one of the fast-growing waste categories in the European Union, with the growth rate of 3-5\% per year (Eurostat, 2018). It is about 3 times higher than the rate of municipal waste. This is the result of massive production of the WEEE and its market expansion based on the technological progress.

PCBs are the fundamental components of any Electrical and Electronic Equipment (EEE); they represent about $3 \mathrm{wt} \%$ of the total electronic waste but they contain precious metals such as gold, silver and palladium as well as base metals such as copper (Kaya, 2016). Thus, there is a huge need and potential for recovering valuable materials from WEEEs. Generally, PCB recycling, finalized to recover metallic fractions includes three stages: the process starts with the pre-treatment which include composition analysis and selective disassembly (Kaya, 2016). Then PCBs are reduced in size through mechanical / physical processes such as shredding, crushing, pulverizing and screening (Duan et al., 2015; Ogunniyi et al., 2009; Wen et al., 2005; Zhao et al., 2004). Finally, chemical treatments are carried out (i.e. pyrometallurgical and hydrometallurgical processes) (Lister et al., 2014; Veit et al., 2006). However, their complex and heterogeneous structures (e.g. mixture of number of different metals, plastics, and ceramics in different sizes) and their variation with time, according to technological improvement as well as primary raw material exploitation strategies, lead to the technical difficulties and environmental issues for their effective pre-concentration stages to improve their recycling. One of the limitations is a lack of proper characterization method to quantitatively evaluate the distribution and liberation/association of different components that are spatially different/heterogeneous, without performing strong milling actions.

There are different categories of particle characterization that can be summarized in: destructive and non-destructive ones, as well as those based on imaging and image analysis (Otsuki et al., 2014). In both case, any information about elemental concentration/distribution or 
similar information inside the particles, can be collected. Destructive methods are usually based on the preliminary sample dissolution into acid and the further measurement of the elemental composition by using a chemical method (e.g. atomic absorption spectroscopy, inductively coupled plasma atomic emission spectrometry). Average values of the different metals, referred to a specific sample, is thus obtained.

Non- destructive methods, quick and easy to apply in terms of particle manipulation, can be directly applied without performing any acid digestion. Among them, the most commonly utilized method is X-Ray Fluorescence (XRF). This elemental analysis is based on measurement of the intensities of the X-rays emitted by secondary excitation. The primary beam irradiates the specimens exciting chemical elements to emit secondary spectral lines that have characteristic wavelengths for each element and intensities related to their concentration. Imaging and image analysis that are major point of this study can be performed with the particles immobilized into resin or mobile particles dispersed under the imaging equipment, such as optical microscope, scanning electron microscope. Following this approach, it is then possible to identify the particle liberations/associations that can be spatially heterogeneous. In this paper, we propose a couple of new solutions belonging to this latter approach, i.e. imaging based methods, using X-Ray based analytical devices.

All the analytical tests were carried out with the samples resulting from processing steps specifically set up to selectively concentrate and recover valuable metals from Printed Circuit Boards (PCBs). More specifically in this work we focused on discussing the applications of different non-destructive characterization methods (laboratory and large scale facility based) to study and understand the liberation and metal/non-metal deportment. Those methods can be applied in different stages of the beneficiation (milling and sieving in this specific case study), in order to enhance the metal recovery for recycling purpose.

The degree of liberation, indicating how much the target component is liberated from the non- 
valuable components, is one of the most important factors to determine the successful

102 enrichment of metals through the subsequent processes, such as physical separation and 103 hydrometallurgical process (Koyanaka et al., 2006; Duan et al., 2009; Otsuki et al., 2014).

104 There are two major methods, both applied in the mineral processing sector, to analyze the 105 degree of liberation of a component in a sample. They are area counting (e.g. Goodall et al., 106 2005) and particle counting (e.g. Abouzeid, 1990). The first method analyzes the surface area of 107 target component/mineral according to the total surface area of the particles containing the target 108 investigated. It has been utilized in the major liberation analyzers associated with the automated 109 Scanning Electron Microscopy (SEM) systems. The current trend in the mineral liberation 110 analysis is shifted towards the generation of large data sets through this automated SEM, such as 111 MLA/QEM-SCAN (e.g. Goodall and Scales, 2007; Otsuki et al., 2014). This system was 112 developed to analyze the liberation of minerals and have been attracting a lot of attention from 113 both the industry and academic. However, it can be easily identified the potential "intrinsic" 114 difficulty in its application to the analysis of complex electronic wastes due to the nature of 115 samples, furthermore the associated analytical software is specifically designed and set up to 116 analyze only minerals.

117 The second method, i.e. particles counting, analyzes the number of particles containing the 118 target material liberated over the total number of particles containing the target material 119 (Abouzeid, 1990). This approach can be associated with the computer aided optical microscopy. 120 Both the previously mentioned approaches are 2D based. A 3D based analytical techniques can 121 also be utilized, that is tomography proposed to apply in this paper for the determination of 122 degree of liberation of mechanically processed PCB particles for the first time as far as the 123 authors' best knowledge.

124 Tomography is another characterization approach to apply. It is a non-destructive method to 125 image the internal structure of an object by the irradiation of X-ray/neutron. The images of the 
analyzed samples are thus displayed with different grey level tones depending on the constituting

127 materials characteristics. Lin and Miller (1996) showed the importance of the determination of

128 the degree of liberation through the evaluation of the volumetric mineral grade distribution,

129 starting from the evaluation of the images (i.e. layers), exhibiting significant grey level

130 differences, of particles constituted by dolomite and sphalerite. The same approach is difficult to

131 achieve for particles resulting from the comminution of complex and heterogeneous electronic

132 wastes. Printed circuits boards can be characterized due to the presence of several

133 matrices/materials/elements (i.e. plastics, metals. alloys, etc.) presenting a different response to

134 X-ray. Zeng et al. (2016) analyzed uncrushed printed circuit boards utilizing a 3D analytical

135 approach based on the Cone Beam Computed Tomography. They worked on the contrast

136 characteristics of the 3D images trying to identify the difference in chemical compositions, based

137 on the differences in the grey levels. Their study did not allow to associate brightness (i.e. image

138 grey level values and resulting voxels associated to the 3D reconstruction) to particles'

139 compositions. On the other hand, this aspect is of great relevance to perform PCBs milled

140 products (i.e. particles) composition determination and material/element deportment and

141 liberation/association assessment as performed in this work for the first time.

142 Within the above outlined frame, this study analyzed the liberation of metals in comminuted

143 PCBs by hammer mills, using (a) a bench top micro XRF mapping and performing elemental

144 analysis by a portable XRF, (b) optical microscopy based imaging and (c) 3D reconstructed

145 images obtained from Synchrotron X-Ray Tomography. The results of all the procedures were

146 finally discussed with specific reference to the metal degree of liberation and different metal

147 associations. The advantages and disadvantages of the three different methods proposed were 148 also discussed as a summary of the work.

\section{MATERIALS AND METHODS}




\subsection{Materials}

Printed circuit boards (origin confidential) were comminuted through shredding and hammer

152 milling followed by sieving. The shredder (Broyeurs-Compacteurs-Destructeurs, BLik) with six

153 thick rotary blades, and equipped with a round sieve opening of $1 \mathrm{~cm}$, was used to crush PCB

154 particles. The hammer mills used were Broyeur Raymond (Laboratoire Stein et Roubaix; called

155 HM1 in this article) with 12 hammers, $5 \mathrm{~mm}$ round sieve openings and approximately $630 \mathrm{~cm}^{3}$

156 free space inside and AR6539 (FORPLEX 00; called HM2 in this article) with 6 hammers, 1.5

$157 \mathrm{~mm}$ round sieve openings, $10 \mathrm{~cm}$ mill diameter. Hammer milling has been reported as a selective

158 liberation method for metals from PCBs based on the impact force applied through rotating

159 hammers (e.g. Koyanaka et al., 2006; Otsuki et al., 2019-a; Otsuki et al., 2019-b). In this study,

160 two size fractions (i.e. $0.125-0.350 \mathrm{~mm}, 0.350-0.500 \mathrm{~mm}$ ) were selected based on our

161 preliminary study identifying the significant difference in the degree of liberation in order to

162 demonstrate the three different approaches to determine the degree of liberation (Eq.1;

163 Abouzeid, 1990).

164

$$
\text { Degree of Liberation }=\frac{N_{\text {unlackad }}}{N_{\text {nnlackesi }}+N_{\text {lackent }}} \times 100(\%)
$$

166 Where ' $N$ unclocked', indicates the number of free particles of the metal of interest and ' $N_{\text {locked' }}$ is

167 the number of interlocked particles, either with other metals or with non-metallic fraction, i.e.

168 plastics, glass and ceramics.

169 In this study, three different methods were performed in order to identify valuable materials

170 for recovery and to evaluate the degree of liberation in two different size fractions. Finally, the

171 results obtained were compared. The three methods are: micro XRF (sections 2.2 .2 and 3.2),

172 optical microscopic analysis (sections 2.3 and 3.3), tomography (sections 2.4 and 3.4). Also, a

173 square peace cut off from the uncrushed PCB was used to analyze the elemental composition 
174 prior to the comminution. X-ray fluorescent (XRF) analysis was applied to evaluate the

175 elemental composition of the uncrushed and crushed PCBs.

176

177

178

179

180

181

182

183

184

185

186

187

188

189

190

191

192

193

194

195

196

\subsection{Methods}

\subsubsection{Elemental analysis: portable XRF}

XRF measurements for crushed PCB particles and uncrushed PCB characterization were performed with the portable XRF machine (Niton XL3t GOLDD+, Thermo Scientific) in-stand where the analyser was locked on a stationary stand and remotely operated through a connected PC. The Mining $\mathrm{Cu} / \mathrm{Zu}$ testing mode equipped the full fundamentals parameter algorithm was used and the measurement duration was $120 \mathrm{~s} /$ point. Particles were put into a plastic container with X-ray thin film (TF-160-255, MYLAR, Port St. Lucie, FI, USA) window facing the X-ray beam and they were measured to have the elemental composition. The minimum 5 points from each sample were measured while their average and $95 \%$ confidence interval were calculated. For the uncrushed PCB, 20 different points were measured while their average and 95\% confidence interval were also calculated.

\subsubsection{Elemental analysis: Micro XRF}

Micro X-Ray Fluorescence (micro-XRF) can be used to analyse both qualitative and quantitative composition of samples and allows high sensitive and non-destructive analysis of elemental composition (Bruker, 2010). In this study, chemical composition and element distribution were obtained using a Bruker M4 Tornado micro X-ray-fluorescence with a Rhodium filament. The applied measurement conditions for the analyses were: pixel time 6 ms/pixel, high voltage $40 \mathrm{kV}$, anode current $500 \mu \mathrm{A}$, step size $50 \mu \mathrm{m}$, and cycles 2 .

Micro-XRF was applied to obtain the chemical maps of the PCB samples. With the M4 Tornado software, these results can be presented as element distribution maps with element intensities in 
197 false colors. Using micro-XRF to produce element maps is a potentially way of determining the

198 elements present and their distribution in the sample.

199

\subsubsection{Sample preparation}

The micro-XRF analysis was carried out for uncrushed PCB in order to obtain the complete mapping. Crushed PCB particles were gently mixed and a small portion was dispersed on a plexiglass support. In some cases, overlapped particles were manually separated by using a spatula. To avoid particle dispersion and their movement during acquisitions, the plexiglass support was lined with a transparent film (Supplementary Figure 1). At the end of this sample preparation procedure, the micro-XRF analysis was performed to evaluate the elemental composition.

\subsubsection{Particle counting}

The ImageJ, 64-bit version Java 1.8.0_112 (70MB), was used for particle counting. The manual counting method was used by the "Cell counter" plug-in (Plugin - Analyze - Cell Counter). This plug-in consists of increasing the number of particle as they are selected by the user. For example, Figure 1 shows the procedure used to calculate the number of particles present in the samples analysed.

\subsection{Optical microscopic analysis}

Fig. 1 goes here.

A binocular optical microscope was used to capture images for their analysis to perform the liberation analysis of mechanically processed PCB particles. The optical microscope (Nikon SMZ 1000 with the eyepieces C-W10xB/22 Nikon) with objective lens (Plan Apo 1xWD70, 
Nikon) was used. It was connected to a PC with the digital camera head (Digital Sight DS-Ri1,

221 Nikon) to save images as digital data. The light source was given by using KL 1500 LCD

222 SCHOOT. The details of the analysis will be given in the following sections.

223

224

225

226

227

228

230

231

232

233

\subsubsection{Sample preparation}

The aim of optical microscopic observation was to count metal, non-metal, and locked particles and total number of particles by observing representative samples of the crushed PCB particles, and to calculate the degree of liberation. The comminuted sample stored in a plastic container was gently mixed, its small portion was taken, and gently dispersed on a glass petri dish to aim one particle layer without overlapping. In addition, if necessary, overlapped particles were manually separated by using a spatula prior to the commencement of image acquisition. Then, particles are ready to observe under the microscope.

The optical microscope was focused on particles and start taking images. A series of images of the sample was taken aiming to capture approximately 1000 particles and build a map of particle images. The particle numbers were aimed to count enough number of particles to achieve a statistically representative analysis.

\subsubsection{Particle counting}

Images taken at different spots of a sample were merged, and the number of aluminum, copper and other type of metallic particles (e.g. alloys) were counted with the software ImageJ after the analysis preparation steps being introduced in the following sections.

The aim of this work is to evaluate the degree of liberation of metal particles; thus, the composite particles (e.g. plastic-metal composite) were considered as locked particles. The direct use of the image analysis software to process a raw image could not be achieved. The ImageJ software can recognize the shape, the brightness and the color of the particles. Thus, for example, a composite of three particles is defined as 3 separated particles according to the 
244 software regardless the fact that they are locked. Such analysis is inappropriate and its correction 245 was necessary. In addition, the contrast between particles and the background was not very high. 246 Black plastics coexisted with white and clear white plastics; thus, a black or a white background 247 cannot help to improve the contrast of all the particles. Supplementary Figure 2 shows the optical 248 microscopic images of crushed PCB particles in 0.125-0.350 $\mathrm{mm}$ size fraction. The other graphic 249 software (Inkscape) was used to manually identify individual particles prior to particle counting. 250 To solve the problems of the direct analysis with the ImageJ, small dots with different colors were plotted on top of each image (Figure 2 (a)) with another software Inkscape to identify the particles before counting with the ImageJ. Different colors were assigned to the different types of particles (e.g. metals, plastics) and their liberations/associations (i.e. liberated, locked). Then,

254 the number of particles can be counted directly by using the ImageJ software upon keeping the 255 dots with applying a white background.

256 Each image was binarized using the ImageJ software. The color of the particles and their 257 shape can then be easily identified.

258 Inkscape allowed to combine all the images into one file and to build the entire surface to 259 study (Figure 2 (b)). The same particles between different images were identified and counted 260 only once with this method. Plastic particles were identified in pink dots while metallic particles 261 were given in red dots. Lines were also drawn to limit the surface to study when the same particles were observed in different images.

\subsection{Tomography}

267 The images resulting from tomographic analysis showed as the color of plastic particles vary 
between black and grey while metallic particles are seen much more bright. The brightest

269 particles in PCBs accounted for Cu. Stucks of 2D images can be used for 3D reconstruction; but 270 this study worked on mainly 2D images with the use of neighboring images to capture the 271 association of the particles situated in the specific 2D cross sections selected for this 272 investigation. Measurements were made in Pisché beamline at synchrotron Soleil (King et al., 273 2016), a light beam dedicated to X-ray diffraction and tomography by absorption contrast at high 274 level of energy (20-50 keV). This beam line allowed us to optimize the setting for improving the 275 contrast between different particles utilizing the strong X-ray and variety setting options while our preliminary study by using a laboratory X-ray tomography machine showed the difficulty to achieve that objective due to its limitation for distinguish different particles by keeping a good contrast between different particles.

For the sample HM $2 b(0.125-0.350 \mathrm{~mm}), 624$ cross sectional images were made with the sample within a four centimeter high plastic tube. The aim is to analyse different layers of the sample and to realize the same work of particle counting as for optical microscopic observation.

\subsubsection{Particle counting}

The 624 cross sectional images were obtained as a continuous images of the sample. Then, the shape, structure and association of particles were observed and studied. Inkscape was used to identify metal and plastic particles with the same methodology applied to the optical microscopic image analysis. In average 250 particles were counted on each image (the diameter of circular section was $1 \mathrm{~cm}$ ). Eight cross sectional images significantly separated each other were used to count more than 1000 particles for the representative analysis and describe the sample in order to avoid counting the same particles repeatedly from the neighboring images. They are the \#1, 100, 200, 300, 400, 550, 600, and 624. The size of particles in the HM $2 \mathrm{~b}$ sample are below $350 \mu \mathrm{m}$; thus the gap of more than 20 images was enough to observe and count totally different particles.

292 The \#500 had many artefacts, and the measurement was thus replaced by the analysis of the 
image \#550. A typical image after the contrast optimization used for the analyses is given in Fig.

2942 (c) with different color dots assigned to plastic (pink) and metal (red) particles shown in Fig. 2 295 (d).

\section{RESULTS AND DISCUSSION}

\subsection{Portable XRF measurements}

Supplementary Table 1 shows the results of XRF analyses of the crushed PCBs with the hammer mill (a) in comparison with the uncrushed PCB (b). The size of particles are in the range of $0.125-0.350 \mathrm{~mm}$ and $0.350-0.500 \mathrm{~mm}$. The metals with the abundant concentrations were listed. The $\mathrm{Cu}$ is the major element (35\% in uncrushed PCB) of this PCB that corresponds to the optical microscopic observations and agreed with literature (e.g. Ghosh, 2015), followed by Al and Si (Supplementary Table 1). Other metal elements are also detected; but it was hard to

identify as liberated particles under the microscope due to the trace elemental concentration and the possible alloy formation. In this study, we focused on $\mathrm{Cu}$ and $\mathrm{Al}$ for the determination of their degree of liberation.

307 The uncrushed PCB contains nearly three times higher $\mathrm{Cu}$ than the crushed ones. This 308 indirectly indicated that the $\mathrm{Cu}$ was successfully separated into other size fractions from the 309 fractions of $0.125-0.500 \mathrm{~mm}$. There was more than $30 \%$ of copper in the uncrushed PCB 310 determined from the results of the 20 measurements in its different locations. The uncrushed 311 PCB also contained $13 \%$ of sulphur while the crushed PCB contained much smaller than $1 \%$ 312 (results not shown in Supplementary Table 1). This indicates that the rejection of sulphur from 313 the size fractions studied and enrichment in other size fractions. On the other hand, the 314 aluminium concentration in non-treated PCB was close to two times smaller than the one in the 315 crushed PCB (1.6\% to $3.1-4.5 \%$ in $0.125-0.50 \mathrm{~mm}$ ). This means that the aluminium was 316 enriched into the size fraction studied after the hammer milling, especially in $0.125-0.350 \mathrm{~mm}$. 
The elemental concentration in this uncrushed PCB varied: the $95 \%$ confidence interval of $\mathrm{Cu}$

318 was $4.95 \%$ while the one of $\mathrm{Al} \%$ was 0.15 from the measurement of 20 different locations.

319 Generally speaking, the elemental distribution within the uncrushed PCB is not homogeneous

320 which agreed with the micro-XRF results shown in the section 3.2, and thus studying a series of

321 different spots is required to have statistically representative results and capture the clear idea of

322 their compositions. More discussion on the portable XRF results can be found in (Otsuki et.al, 323 2019-a).

\subsection{Micro XRF measurements}

325

\subsubsection{Uncrushed PCB}

Figure 3 shows the digital image and micro-XRF elemental mapping, indicating the element distributions of the uncrushed PCB. The micro-XRF analysis made it possible to identify the chemical elements and to associate them with their functions.

The copper $(\mathrm{Cu}$, Figure $3(\mathrm{c}))$ is the major element of this PCB due to its good characteristics of electrical and thermal conductivity. The superficial green layer of PCB is called solder mask. It is a thin layer of polymer, like a lacquer, which is applied in PCBs to protect against the oxidation and to avoid the formation of bridges between close welds (Mitzner, 2009). The solder mask contains silicon ( $\mathrm{Si}$, Figure 3 (f)), which is used to control the viscosity of the liquid welding mask before polymerization, barium (Ba, Figure $3(\mathrm{~d})$ ) and sulfur (S, Figure 3 (f)), used as a flame retardant (Woolley, 2013). The serigraphy (letters, numbers and symbols) that identifies the components on the board, is made of titanium (Ti, Figure 3 (e)).

Fig. 3 goes here. 
conductive, superconductivity, piezoelectric and magnetic properties which made them

342 fundamental materials for microchips and other components present in printed circuits. A

343 ceramic material usually consists of a metallic element and a non-metallic element, such as $\mathrm{SiO}_{2}$

344 or $\mathrm{Al}_{2} \mathrm{O}_{3}$ (Veit and Bernardes, 2015). In fact, Figure 3 (f) indicates the presence of silicon in the

345 chips mounted on the board. In the assembly and interconnection of silicon chips, welding plays

346 a crucial role. The soldering based on lead and tin $(63 \% \mathrm{Sn}$ and $37 \% \mathrm{~Pb})$ are the classic

347 connection material; Figure $3(\mathrm{~g})$ show the presence of tin $(\mathrm{Sn})$ and lead $(\mathrm{Pb})$ based solders used

348 for the connection. The sample also contains the bromine ( $\mathrm{Br}$, Figure $3(\mathrm{~h}))$. Bromine is used as a

349 flame retardant, in order to prevent the propagation of an accidental combustion in the electric

350 circuits of electrical and electronic equipment. Noticeable and aligned $\mathrm{Br}$ concentration was

351 identified. One can see the PCB producer's intention to segregate several different small

352 equipment colonies to avoid the fire propagation to all the surface. About precious metals such as

353 silver $(\mathrm{Ag})$ and gold $(\mathrm{Au})$, they are found in specific areas such as inside the microprocessor

354 circuit and in contacts. Specifically, connector pins are made of gold and nickel alloy while the 355 gold present in the microprocessor is pure (Figure 3 (j)).

\subsubsection{Crushed PCB}

The two different particles size classes (i.e. $0.125-0.350 \mathrm{~mm}, 0.350-0.500 \mathrm{~mm}$ ) were analyzed, using micro-XRF based mapping in order to identify the alloys, the metals constituting the individual particles and thus the degree of liberation. The analysis showed that most of the

360 metallic particles were weakly locked $(<20-30 \%$ of particle surface) with plastic, glass fiber, or

361 other metals, in different degrees. The majority of those composites contain small quantities of 362 secondary element (e.g. Br in $\mathrm{Cu}$ host in Figs. 4 (b); $\mathrm{Si}$ and $\mathrm{Ca}$ in $\mathrm{Al}$ host in Fig. 4 (d)) that are 363 hard to recognize under the optical microscope due to their small quantities and similar optical 364 properties with the host material most of the cases. Degree of liberation varies with the type of 365 elements (i.e. $\mathrm{Cu}, \mathrm{Al}$, other metals) and particle size. Figure $4 \mathrm{a}, 4 \mathrm{~b}, 4 \mathrm{c}$ and $4 \mathrm{~d}$ show some locked 
and unlocked $\mathrm{Cu}$ and $\mathrm{Al}$ particles identified in the sample HM2b (0.125-0.350 mm). In general,

367 the combination of micro-XRF mappings and stereomicroscope images can help a good 368 identification of liberation/association of metallic components with the PCB particles 369 mechanically processed.

370 Table 1 summarizes all the results of the analyses carried out on the size fraction $0.125-0.350$ 371 mm (HM2b) by using the combination of stereomicroscope images and micro-XRF mapping.

372 The results indicated that the population of unlocked Al particles $(1.88 \%)$ were twice of the one 373 of $\mathrm{Cu}(0.94 \%)$, out of 319 particles counted, and the degree of unlocked $\mathrm{Al}$ particles $(86 \%)$ was 374 higher than $\mathrm{Cu}(30 \%)$. Their degree of liberation will be further discussed, together with the 375 results of the coarser size fraction $(0.350-0.50 \mathrm{~mm})$.

Fig. 4 goes here.

Figures 4e, 4f, 4g and $4 \mathrm{~h}$ show some locked and unlocked copper and aluminium particles 381 identified in the sample HM2a $(0.35-0.50 \mathrm{~mm})$. Although the trend is similar with the fine size $382(0.125-0.350 \mathrm{~mm}$, Figures 4 (a)-(d)), the analysis showed that composite particles were strongly 383 locked ( $<60-70 \%$ of particle surface) with plastic, glass fiber, or other metals, in wider range of locking degrees (10-70\%) than the fine size fraction (10-30\%, Figures 4 (a)-(d)). Also, more elements are associated with the host metallic element (e.g. $\mathrm{Cu}$ with $\mathrm{Al}, \mathrm{Si}, \mathrm{Ca}, \mathrm{Fe}, \mathrm{Cu}$ and $\mathrm{Br}$ in 386 Figure 4(f); Al with $\mathrm{Si}, \mathrm{Ca}$ and $\mathrm{Fe}$ in Figure 4 (h)) than the ones in fine size fraction (e.g. Cu with $387 \mathrm{Si}, \mathrm{Ca}$ and $\mathrm{Br}$ in Figure 4 (b); Al with $\mathrm{Si}$ and $\mathrm{Ca}$ in Figure 4 (d)). The results indicate as the fine grinding/communication enhances the liberation of $\mathrm{Cu}$ and $\mathrm{Al}$ from other elements.

Table 1 goes here. 
Table 1 also shows the results obtained for the HM2a sample $(0.350-0.500 \mathrm{~mm})$. These show

391 that the population of unlocked $\mathrm{Al}$ particles (1.20\%) were the same as $\mathrm{Cu}(1.20 \%)$, out of 249 particles counted although their degree of liberation is smaller $(15 \% \mathrm{Cu}, 60 \% \mathrm{Al})$ than the ones

393 in the fine size fraction $(30 \% \mathrm{Cu}, 86 \% \mathrm{Al}$ in $0.125-0.350 \mathrm{~mm})$ and will be further discussed 394 together with the results of finer size fraction.

395 The combination of the stereomicroscope and the micro-XRF analyses showed that most of the 396 metallic particles are locked with plastic, glass fiber and/or other metals. This analysis made it 397 possible to determine the distribution of $\mathrm{Cu}$ and $\mathrm{Al}$ in the particles and therefore to evaluate their 398 degree of liberation. As shown in Table 1, in the coarse size fraction $(0.350-0.50 \mathrm{~mm})$, the 399 number of locked particles is higher than the fine size fraction $(0.125-0.350 \mathrm{~mm})$. Table 1 shows 400 the degree of liberation of $\mathrm{Cu}$ and $\mathrm{Al}$, calculated by using the results of the combination of 401 stereomicroscope and micro-XRF mapping. Apart from $\mathrm{Al}$ in $0.125-0.350 \mathrm{~mm}(86 \%)$, the degree 402 of liberation based on this particle counting method is generally low $(\leq 60 \%)$ as shown in the Table 1, since the detection of small quantities of other elements within the host metallic elements $(\mathrm{Cu}, \mathrm{Al})$ decreases the degree of liberation based on the particle counting. Area counting would increase the degree of liberation and the results could be more representative and useful, especially for the separation/process unit operations utilizing surface or bulk properties of materials of our interest (e.g. $\mathrm{Cu}, \mathrm{Al}$ ) for their selective recovery for recycling. The comparison

408 between the particle counting and area counting is out of focus of this paper and will be 409 published in a separate paper.

\subsection{Optical microscope analysis}

411 Table 2 shows the results of particle analysis of the HM2b sample with the size fraction $412 \quad 0.125-0.350 \mu \mathrm{m}$ with the optical microscope. The 18 images were recorded after spreading the 413 particles on a glass surface. In each image, the number of liberated/unlocked and locked copper, 414 aluminium, other metals (e.g. alloys) particles were counted. Then, the percentage of the copper, 
415 aluminium and total metal were calculated for each image and summarized to capture all the 416 information for the entire surface. The results indicated the $\mathrm{Cu} 1.66 \%, \mathrm{Al} 4.15 \%$ were presented 417 as unlocked particles out of 1326 particles counted.

418 The efficiency of hammer milling to liberate metals was determined by calculating the degree 419 of liberation of main metals, i.e. $\mathrm{Cu}, \mathrm{Al}$, alloys. The results showed a high degree of liberation 420 reaching $85 \%$ of $\mathrm{Cu}, 90 \%$ of $\mathrm{Al}$ bearing particles. Thus, in total $89 \%$ of metal particles were 421 liberated in this size fraction after the hammer milling. The precision of the value could depend 422 on the operator. S/he has to identify the locked particles by differences in shape, contrast, 423 brightness and color of the particles within the grains. Then, there are potentially three major 424 source of errors: (1) a size of the plastic or the metal locked in the grain can be relatively small to 425 be distinguished under the optical microscope that aims to capture many particles for a 426 representative measurement; (2) the contrast between copper and black plastic particles is huge 427 and could hinder those plastic particles; (3) 2D image observation that could be difficult to identify whether particles are locked or liberated but simply overlapped or attached by the electrostatic forces. The 3rd issue can be addressed by using the 3D information extracted from 430 tomographic images and applied in this study. Therefore, there has to be a good balance between 431 the number of particles counted and the image quality of the particles. In addition, a proper dispersion of individual particles without overlapping each other is significantly important.

\section{Table 2 goes here.}

The HM2a sample containing coarser particles $(0.350-0.500 \mathrm{~mm})$ was also analyzed in order to compare the results with the finer size fraction $(0.125-0.350 \mathrm{~mm}$, Table 2). Over 28 images

438 taken, 1234 particles were counted and analyzed. Almost all the copper particles were locked 
with plastic or other metals (aluminum, alloys). Also, for aluminum particles or other metals

440 (e.g. tin, alloys), the degree of liberation was low. It means that the size reduction through the 441 hammer milling was not sufficient in this size fraction. Less than $15 \%$ of the copper was 442 liberated while $53 \%$ of aluminum did. In general, the degree of liberation of metals was $45 \%$ that 443 was significantly lower than the value obtained by the finer size fraction $(89 \%$ in $0.125-0.350$ $444 \mathrm{~mm}$ ). The above mentioned trend observed by the optical microscopic image analysis is similar 445 with the results obtained by the combination of the stereomicroscope and micro-XRF imaging 446 although their degree of liberation is higher $(85 \% \mathrm{Cu}$ and $90 \% \mathrm{Al}$ in $0.125-0.350 \mathrm{~mm}$ in Table 2) 447 than the latter combination $(30 \% \mathrm{Cu}$ and $86 \% \mathrm{Al}$ in $0.125-0.350 \mathrm{~mm}$ in Table 1$)$. This can be 448 due to the different nature of the two methods applied, as mentioned in the previous sections, 449 especially in terms of recognition of composite particles.

\section{$450 \quad 3.4$ Tomographic image analysis}

Total 2050 particles were counted over the images of the HM2b $(0.125-0.350 \mathrm{~mm})$ crushed sample. Approximately 250 particles were identified in each image. The challenge was associated with the contrast of each image to identify the dark plastic particles. Some particles seen as isolated in one cross sectional 2D image can be locked with other particles. Thus, the neighboring images were also checked to identify whether they are really isolated or not, with the utilization of the 3D information to track the whole surface of the particles. By knowing such potential errors and utilizing 3D option, the degree of measurement errors kept low with respect to the total number of particles counted in each image. Table 3 contains all the measurement results of particle analysis of the HM2b sample with the size fraction $0.125-0.350 \mathrm{~mm}$ with the 460 tomographic images.

461 Through the analyses of tomographic images, it was rather difficult to distinguish the different 
463

total metal particles (bright particles in tomographic images) was determined. This is different

464 from the case of Lin and Miller (1996) who studied only two mineral components that have the 465 significant grey level difference indicated by the complete spectra isolation. The liberation $\%$ of metal was $80.26 \%$ for 152 particles. The value is close to the one identified with the analysis of the optical microscopic images (89\%), but away from the one obtained with the micro-XRF analysis (54\%). With tomographic images, the identification of the nature of particles is rather limited with the grey scale difference given in the tomographic images due to the limited access to the different range of colors associated with them. On the other hand, utilizing both the grey level and shape of the particles can help us the particle composition. For example, the shape of cable for the brightest particle allows us to identify it as copper cables. With the micro-XRF mapping, the detection of small quantities $(<20-30 \%$ of particle surface) of secondary elements in the host metallic particles (e.g. $\mathrm{Br}$ in $\mathrm{Cu}, \mathrm{Si}$ and $\mathrm{Ca}$ in $\mathrm{Al}$ ) made the degree of liberation by the particle counting method lower than the other two methods.

\section{Table 3 goes here.}

\subsection{Comparison between the analyses using micro XRF and image analyses}

The three methods provided the similar results in terms of the general trend (i.e. higher degree of liberation with fine particles than coarse particles) with some variation in the absolute values in the degree of liberation and some access limitation (i.e. synchrotron X-ray tomography). The micro-XRF results showed the lower degree of liberation values than the other two methods, by particle counting. This is due to the capability of micro-XRF to detect small quantities of secondary material(s) within the host $\mathrm{Cu} / \mathrm{Al}$ particles while those secondary materials can be 
hard to recognize due to their quantities and/or similar optical/physical properties with their host

487 by using either optical microscope or tomography images.

488 In any of the three methods, the experimental work in the above-mentioned image analyses 489 showed that the precision of the data and analysis could depend on the contrast and the 490 resolution of the images. In addition, the preliminary knowledge about the nature of the sample 491 (e.g. composition, association) would be of great help for the better analyses, as applicable to all 492 the other analyses (e.g. electron microscopic analyses). Table 4 shows the summary of 493 advantages and disadvantages of micro-XRF, optical microscopic and synchrotron tomographic 494 image analyses for the mechanically processed PCB particles.

495 The light elements (for example the $\mathrm{C}$ present in the plastics) cannot be analyzed by micro496 XRF because are weak absorbers and relatively strong scatterers of X-rays. During the optical 497 microscopic observations, the presence of the different types of the color and brightness of 498 particles prevented us from select the best background for all the particles in order to maximize

499 the contrast. In tomography, the grey scale and the artifacts made difficult the identification of 500 the light plastic particles seen as dark spots. Meanwhile, it was relatively easy to identify the 501 locked particles with the both optical microscopic and tomographic images while the 502 tomographic images allowed us see the entire structure of each particle using the 3D information 503 captured.

504

505

506

Table 4 goes here. 


\section{CONCLUSIONS}

The degree of liberation of mechanically processed PCB particles were analyzed by using the images obtained by three different methods, including the methodological developments, for the recycling oriented non-destructive characterization. The three methods were: micro-XRF, optical microscope, and synchrotron x-ray tomography.

$$
\text { The micro-XRF analysis provided the elemental distribution maps of the sample surface and }
$$
associate them with their functions. It was possible to identify the materials (ceramics, metals, etc.) that are interesting for the material recovery, determine the distribution of the detected element and evaluate the degree of liberation of copper and aluminum in the PCB samples.

The analyses of tomographic images used mainly 2D cross sectional images but also 3D information to investigate whether particles were liberated or not in their whole surfaces. That is one of the major advantages over the analyses of micro-XRF and optical microscopic images. The other difference is that the utilization of color of the particles in the sample. Optical microscopic images can utilize the variety of colors to distinguish different particles while the tomographic images assign only the grey level difference that makes difficult to distinguish different particles with small grey level difference.

Although the similarities/differences among three methods were discussed, the common issues were also identified. The good knowledge of the sample would be of a great help for the operator to distinguish different particles and decide the particle liberation or locked. On the other hand, their accuracy could depend on the operator's judgment and knowledge about the sample to identify and distinguish different particles and the image resolution. The degree of liberation of metals determined by the optical microscope and tomographic image analyses were very close ( $81 \%$ with tomography; $89 \%$ with optical microscope), but different from the ones obtained through the micro-XRF mapping (54\%) by the particle counting. In general, the metal particle liberation was very high in the fine size fraction while many locked particles were 
534 identified in the coarse size fraction whose trend agreed with the anticipation.

535 Onsite sampling and measurement to evaluate the degree of liberation and processing 536 performance tuning and the metal recovery performance prediction would be highly efficient and 537 beneficial for recycling process in the future. In order to achieve those goals, next steps would 538 be the application of the proposed methods to confirm their applicability to different materials as 539 well as optimization and automation of the image analysis procedures.

\section{ACKNOWLEDGEMENTS}

541 The author would like to acknowledge the contribution from Ms. Lisa Gasser for sample 542 preparation. A part of results in liberation analysis in this article was presented in Sardinia 2017.

543 Tomography measurement was performed in synchrotron SOLEIL in using the beamline Psiché.

\section{REFERENCES}

545 Abouzeid, A.Z.M. (1990). Mineral Processing Laboratory Manual, Trans Tech Publications, $546 \quad$ Clausthal-Zellerfeld, 23-27.

547 Bruker (2010). Physical Principles of Micro-X-ray Fluorescence - M4 Tornado.

548 Eurostat. http://ec.europa.eu/eurostat/web/waste/key-waste-streams/wee, accessed on $549 \quad 18 / 05 / 2018$.

550 Duan, C.L., Diao, Z.J., Zhao, Y.M., Huang, W. (2015). Liberation of valuable materials in waste 551 printed circuit boards by high-voltage electrical pulses. Miner. Eng. 70, 170-177.

552 Duan, C., Wen, X., Shi, C., Zhao, Y., Wen, B., He, Y. (2009). Recovery of metals from waste 553 printed circuit boards by a mechanical method using a water medium. J. Hazardous Materials 554 vol. $166,478-482$.

555 Ghosh, B., Ghosh, M.K., Parhi, P., Mukherjee, P.S., Mishra, B.K. (2015). Waste printed circuit 
boards recycling: an extensive assessment of current status. J. Cleaner Production, vol. 94, 519.

558 Goodall, W.R., Scales, P.J. (2007). An overview of the advantages and disadvantages of the 559 determination of gold mineralogy by automated mineralogy. Miner. Eng., vol. 20, 506-517.

560 Goodall, W.R., Scales, P.J., Butcher, A.R. (2005). The use of QEMSCAN and diagnostic 561 leaching in the characterization of visible gold in complex ores. Miner. Eng., vol. 18, 877562886.

563 Kaya, M. (2016). Recovery of metals and nonmetals from electronic waste by physical and 564 chemical recycling processes. Waste Manag. 57, 64-90.

565 King, A., et al. (2016). Tomography and imaging at the PSICHE beam line of the SOLEIL 566 synchrotron. Rev. Sci. Instrum., vol. 87, 093704.

567 Koyanaka, S., Endoh, S., Ohya, H. (2006). Effect of impact velocity control on selective 568 grinding of waste printed circuit boards. Adv. Powder Technol. 17, 113-126.

569 Lin, C.L., Miller, J.D. (1996). Cone beam X-ray microtomography for three-dimensional $570 \quad$ liberation analysis in the 21st century. Int. J. Miner. Process., vol. 47, 61-73.

571 Lister, T.E., Wang, P., Anderko, A. (2014). Recovery of critical and value metals from mobile electronics enabled by electrochemical processing. Hydrometallurgy 149, 228-237.

Mitzner, K. (2009). Complete PCB Design Using Or CAD Capture and layout. Elsevier Inc.

574 Ogunniyi, I.O., Vermaak, M.K.G., Groot, D.R. (2009). Chemical composition and liberation 575 characterization of printed circuit board comminution fines for beneficiation investigations. Waste Manag. 29, 2140-2146.

Otsuki, A. Chen, Y., Zhao Y. (2014). Characterisation and beneficiation of complex ores for sustainable use of mineral resources: refractory gold ore beneficiation as an example. Int. J. Soc. Mater. Eng. Resour., vol. 20, 126-135.

Otsuki, A., Gonçalves, P.P., Stieghorst, C., Révay, Z. (2019-a). Non-Destructive 
Characterization of Mechanically Processed Waste Printed Circuit Boards: X-ray Fluorescence Spectroscopy and Prompt Gamma Activation Analysis. J. Compos. Sci., vol. 3, 54.

Otsuki, A., Gonçalves, P.P., Leroy E. (2019-b). Selective Milling and Elemental Assay of 585 Printed Circuit Board Particles for Their Recycling Purpose. Metals vol.9, 899.

Woolley, M. (2013). Corrosives on a PCB: Finding the source. https://www.edn.com.

Veit, H.M., Bernardes, A.M., Ferreira, J.Z., Tenório, J.A.S., de Fraga Malfatti, C. (2006). Recovery of copper from printed circuit boards scraps by mechanical processing and electrometallurgy J Hazard Mater, vol 137, 1704-1709.

Veit, H.M., Bernardes, A.M. (2015). Electronic waste. Recycling Techniques. Topics in Mining, 591 Metallurgy and Materials Engineering. Series Editor: Carlos P. Bergmann. Springer.

592 Wen, X., Duan, C., Jiao, H., Zhao, Y., Zhou, X., Song, S. (2005). Study on metal recovery from 593 discarded printed circuit boards by physical methods. Proceedings of IEEE International 594 Symposium on Electronics and the Environment, 121- 128.

595 Zeng, L., Yan, B., Wang, W. (2016). Contrast Enhancement Methods Based on Gray and Its 596 Distance Double-Weighting Histogram Equalization for 3D CT Images of PCBs. 597 Mathematical Problems in Engineering Vol. 2016, Article ID 1529782.

598 Zhao, Y., Wen, X., Li, B., Tao, D. (2004). Recovery of copper from printed circuit boards. $599 \quad$ Miner Metall Proc 21, 99-102.

600

601

602

603

604

605 
Table 1. Metal and plastic particles counted using the stereomicroscope images and micro-XRF mapping,

609 and calculated degree of liberation of metals in hammer mill products $0.125-0.350 \mathrm{~mm}(\mathrm{HM} 2 \mathrm{~b})$ and

610 0.350-0.500 mm (HM2a).

\begin{tabular}{|c|c|c|c|c|c|c|c|c|c|}
\hline \multirow[t]{2}{*}{$\begin{array}{c}\text { Particle } \\
\text { size }\end{array}$} & \multicolumn{3}{|c|}{$\mathrm{Cu}$} & \multicolumn{3}{|c|}{ Al } & \multirow{2}{*}{$\begin{array}{c}\text { Total } \\
\text { number } \\
\text { of } \\
\text { particles } \\
\text { counted }\end{array}$} & \multicolumn{2}{|c|}{$\begin{array}{c}\% \text { unlocked } \\
\text { particles against } \\
\text { total number of } \\
\text { particles } \\
\text { counted }\end{array}$} \\
\hline & Unlocked & Locked & $\begin{array}{c}\text { Degree of } \\
\text { liberation } \\
(\%)\end{array}$ & Unlocked & Locked & $\begin{array}{c}\text { Degree of } \\
\text { liberation } \\
(\%)\end{array}$ & & $\mathrm{Cu}$ & Al \\
\hline 0.125 & & & & & & & & & \\
\hline $\begin{array}{c}- \\
0.350 \\
\mathrm{~mm}\end{array}$ & 3 & 7 & 30 & 6 & 1 & 86 & 319 & 0.94 & 1.88 \\
\hline 0.350 & & & & & & & & & \\
\hline $\begin{array}{c}- \\
0.500 \\
\mathrm{~mm}\end{array}$ & 3 & 17 & 15 & 3 & 2 & 60 & 249 & 1.20 & 1.20 \\
\hline
\end{tabular}

611

612

613

614

615

616

617

618

619

620

621

622 
Table 2. Metal particles counted using the optical microscopic images, and calculated degree of liberation of metals in hammer mill products $0.125-0.350 \mathrm{~mm}$ (HM2b) and 0.350-0.500 mm (HM2a).

\begin{tabular}{|c|c|c|c|c|c|c|c|c|c|}
\hline \multirow[t]{2}{*}{$\begin{array}{c}\text { Particle } \\
\text { size }\end{array}$} & \multicolumn{3}{|c|}{$\mathrm{Cu}$} & \multicolumn{3}{|c|}{ Al } & \multirow{2}{*}{$\begin{array}{c}\text { Total } \\
\text { number } \\
\text { of } \\
\text { particles } \\
\text { counted }\end{array}$} & \multicolumn{2}{|c|}{$\begin{array}{c}\% \text { unlocked } \\
\text { particles against } \\
\text { total number of } \\
\text { particles } \\
\text { counted }\end{array}$} \\
\hline & Unlocked & Locked & $\begin{array}{c}\text { Degree of } \\
\text { liberation } \\
(\%)\end{array}$ & Unlocked & Locked & $\begin{array}{c}\text { Degree of } \\
\text { liberation } \\
(\%)\end{array}$ & & $\mathbf{C u}$ & Al \\
\hline 0.125 & & & & & & & & & \\
\hline $\begin{array}{c}- \\
0.350 \\
\mathrm{~mm}\end{array}$ & 22 & 4 & 85 & 55 & 6 & 90 & 1326 & 1.66 & 4.15 \\
\hline 0.350 & & & & & & & & & \\
\hline $\begin{array}{c}- \\
0.500 \\
\mathrm{~mm}\end{array}$ & 10 & 59 & 14 & 46 & 41 & 53 & 1234 & 0.81 & 3.73 \\
\hline
\end{tabular}


643 Table 3. Metal and plastic particles counted using the tomographic images. Sample HM2b (0.125-0.350 $644 \mathrm{~mm})$.

\begin{tabular}{|c|c|c|c|c|c|}
\hline \multirow{3}{*}{$\begin{array}{c}\text { Image } \\
\text { number }\end{array}$} & \multicolumn{3}{|c|}{ Number of particles } & \multirow{3}{*}{$\begin{array}{l}\% \text { unlocked metal particles } \\
\text { against total number of } \\
\text { particles counted }\end{array}$} & \multirow{3}{*}{$\begin{array}{l}\text { Degree of } \\
\text { liberation } \\
\quad(\%)\end{array}$} \\
\hline & \multicolumn{2}{|c|}{ Metal } & \multirow[t]{2}{*}{ Total } & & \\
\hline & Unlocked & Locked & & & \\
\hline 1 & 9 & 2 & 266 & 3.38 & 81.82 \\
\hline 100 & 12 & 2 & 260 & 4.62 & 85.71 \\
\hline 200 & 9 & 3 & 330 & 2.73 & 75.00 \\
\hline 300 & 16 & 3 & 260 & 6.15 & 84.21 \\
\hline 400 & 13 & 6 & 260 & 5.00 & 68.42 \\
\hline 550 & 18 & 2 & 206 & 8.74 & 90.00 \\
\hline 600 & 21 & 5 & 247 & 8.50 & 80.77 \\
\hline 624 & 24 & 7 & 221 & 10.86 & 77.42 \\
\hline TOTAL & 122 & 30 & 2050 & 5.95 & 80.26 \\
\hline
\end{tabular}

645

646

647

648

649

650

651

652

653

654

655

656

657 
Table 4. Advantages and disadvantages of micro-XRF, optical microscopic and tomographic image analyses for mechanically processed printed circuit board particles.

\begin{tabular}{|c|c|c|c|c|c|}
\hline \multicolumn{2}{|c|}{ Micro XRF } & \multicolumn{2}{|c|}{ Optical microscope } & \multicolumn{2}{|c|}{ Synchrotron tomography } \\
\hline Advantages & Drawbacks & Advantages & Drawbacks & Advantages & Drawbacks \\
\hline $\begin{array}{l}\text { Fast multi- } \\
\text { elemental and } \\
\text { non-destructive } \\
\text { analysis. } \\
\text { No need of } \\
\text { sample } \\
\text { preparation. }\end{array}$ & $\begin{array}{l}\text { Light elements } \\
(\mathrm{Li}, \mathrm{Be}, \mathrm{B}, \mathrm{C}, \mathrm{N}, \\
\mathrm{O} \text { and } \mathrm{F}) \text { are } \\
\text { weak absorbers } \\
\text { and relatively } \\
\text { strong scatterers } \\
\text { of X-rays, cannot } \\
\text { be analyzed. }\end{array}$ & $\begin{array}{l}\text { Particles can be } \\
\text { directly } \\
\text { manipulated to } \\
\text { disperse under } \\
\text { the microscope } \\
\text { prior to the } \\
\text { commencement } \\
\text { of the image } \\
\text { acquisition. }\end{array}$ & $\begin{array}{l}\text { Results could } \\
\text { depend on the } \\
\text { operator's skill } \\
\text { and knowledge } \\
\text { about the } \\
\text { sample. }\end{array}$ & $\begin{array}{l}\text { Large number of } \\
\text { particles can be } \\
\text { imaged in a } \\
\text { short period of } \\
\text { time. }\end{array}$ & $\begin{array}{l}\text { Difficulty to } \\
\text { distinguish } \\
\text { different } \\
\text { metals using } \\
\text { their } \\
\text { differences in } \\
\text { grey levels in } \\
\text { the presence } \\
\text { of many } \\
\text { different } \\
\text { components. }\end{array}$ \\
\hline $\begin{array}{l}\text { The creation of } \\
\text { elemental maps } \\
\text { was realized to } \\
\text { check the } \\
\text { chemical } \\
\text { composition and } \\
\text { its } \\
\text { distribution/assoc } \\
\text { iation. }\end{array}$ & $\begin{array}{l}\text { The detection } \\
\text { limit (LOD) for } \\
\text { heavy elements is } \\
\text { greater than } 20 \\
\text { ppm. }\end{array}$ & $\begin{array}{l}\text { Access to the full } \\
\text { color range of the } \\
\text { particles in the } \\
\text { sample. }\end{array}$ & $\begin{array}{l}\text { Time } \\
\text { consuming; use } \\
\text { of 2D image } \\
\text { could be } \\
\text { difficult to } \\
\text { study } \\
\text { overlapped } \\
\text { particles and } \\
\text { particle } \\
\text { association in } \\
\text { the vertical } \\
\text { direction. }\end{array}$ & $\begin{array}{l}\text { 3D image } \\
\text { acquisition to } \\
\text { study the whole } \\
\text { particle surface. }\end{array}$ & $\begin{array}{l}\text { Resolution } \\
\text { depending on } \\
\text { the machine } \\
\text { and setting. }\end{array}$ \\
\hline
\end{tabular}




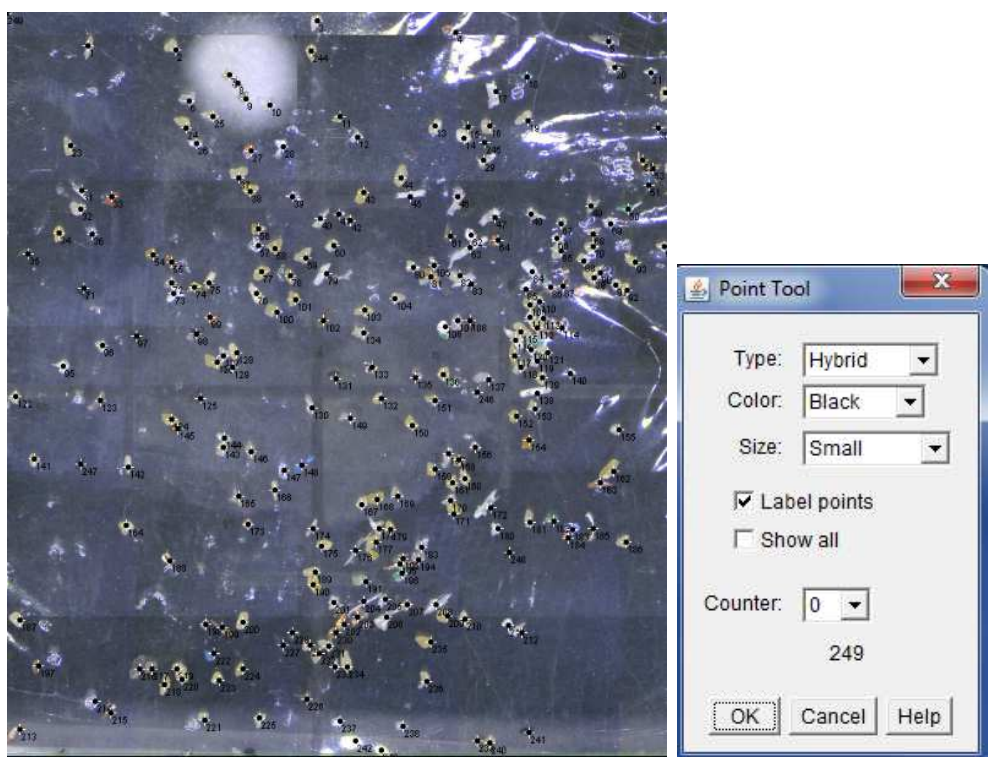

Fig. 1. Particle counting using the "Cell counter" plug-in inside ImageJ environment.

676

677

678

679

680

681

682

683

684

685 


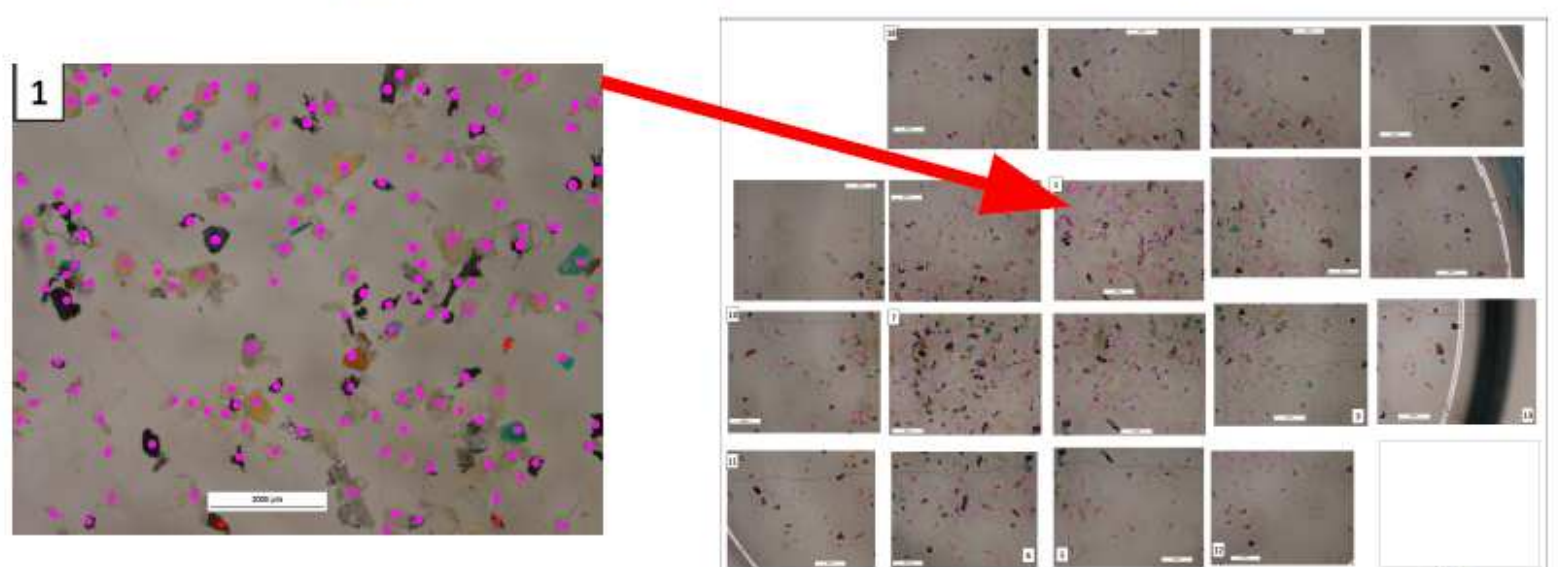

(a)

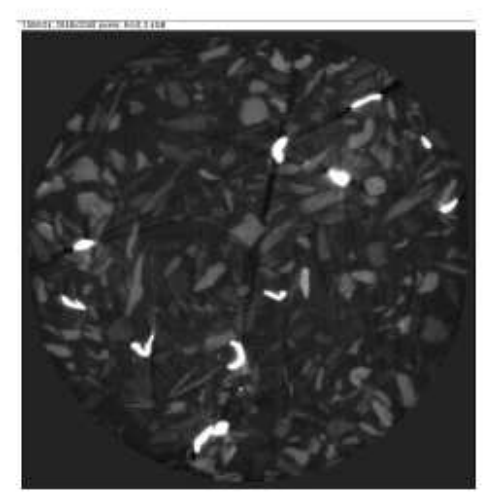

(c) (b)

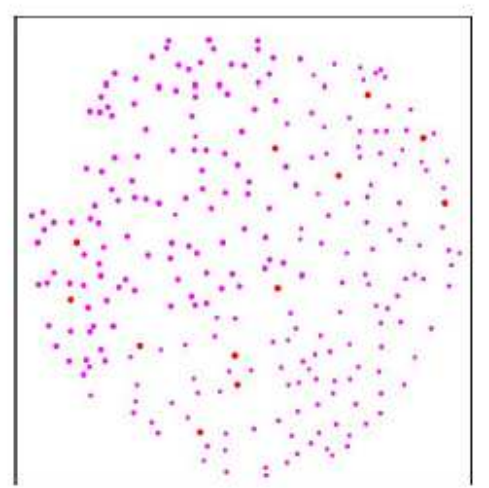

(d)

689 Fig. 2. (a) Individual particles assigned with dots, and (b) combined images with the dots. Sample HM2b $690 \quad 0.125-0.350 \mathrm{~mm}$. (c) A cross section of tomographic image after contrast adjustment and (d) dots 691 assigned for particles. Sample HM2b 0.125-0.350 mm. 
697

698

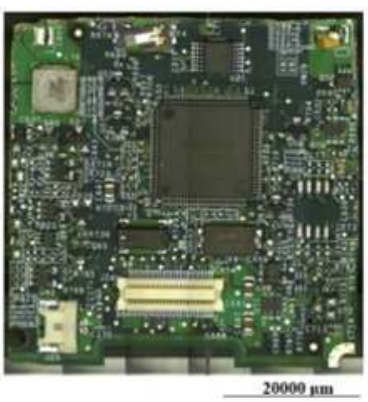

Digital image

(a)

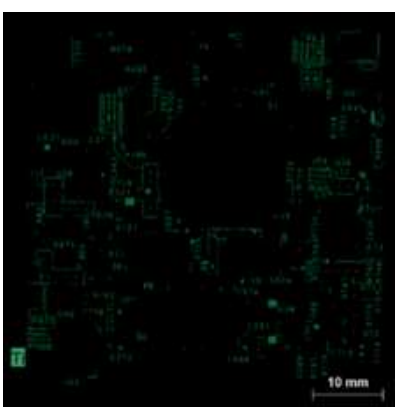

$\mathrm{Ti}$

(e)

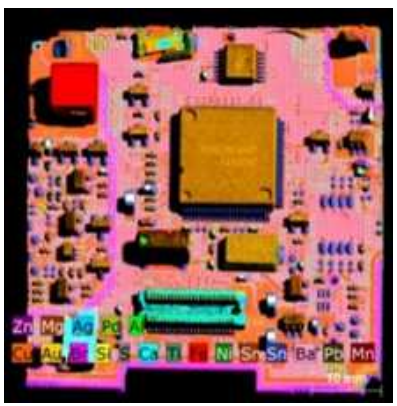

Total map

(b)

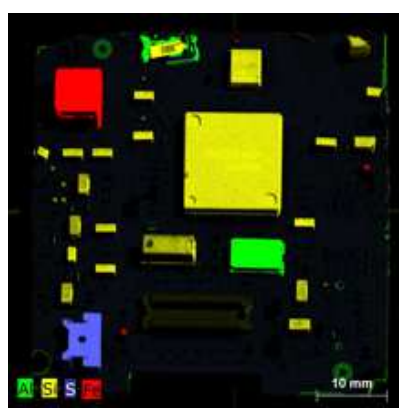

$\mathrm{Al}, \mathrm{Si}, \mathrm{S}$ and $\mathrm{Fe}$

(f)

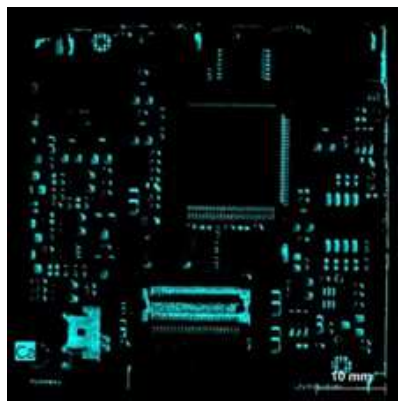

$\mathrm{Ca}$

(i)

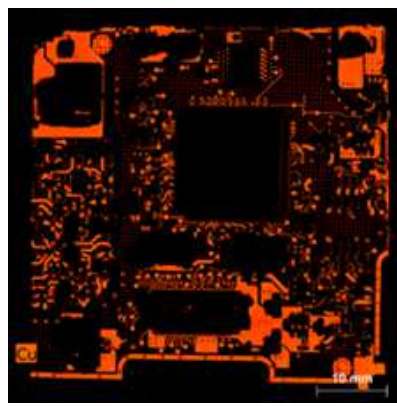

$\mathrm{Cu}$

(c)

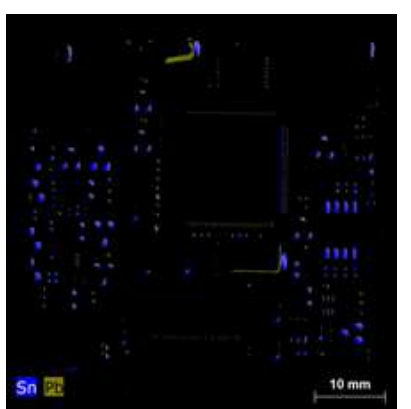

$\mathrm{Sn}$ and $\mathrm{Pb}$

(g)

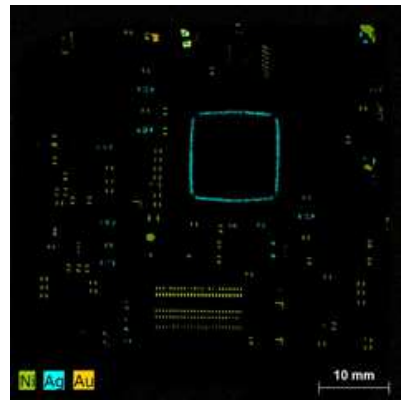

$\mathrm{Ni}, \mathrm{Ag}$ and $\mathrm{Au}$

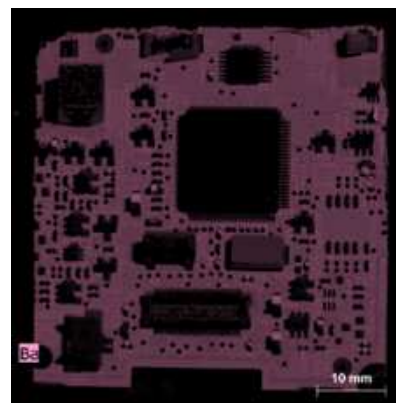

$\mathrm{Ba}$

(d)

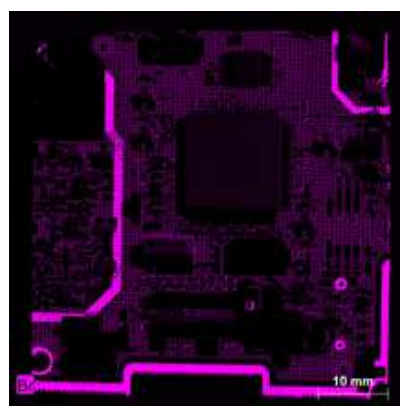

$\mathrm{Br}$

(h)

(j)

699 
706

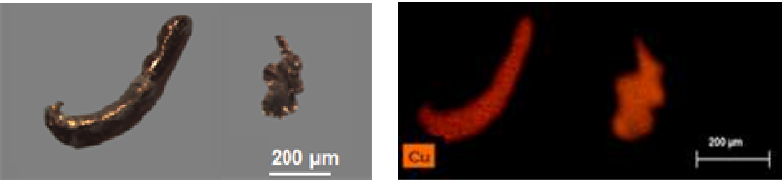

(a)

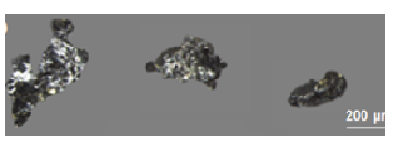

(c)

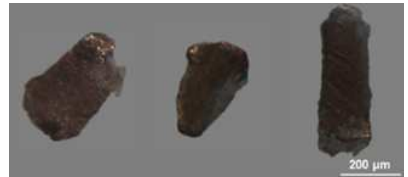

(b)
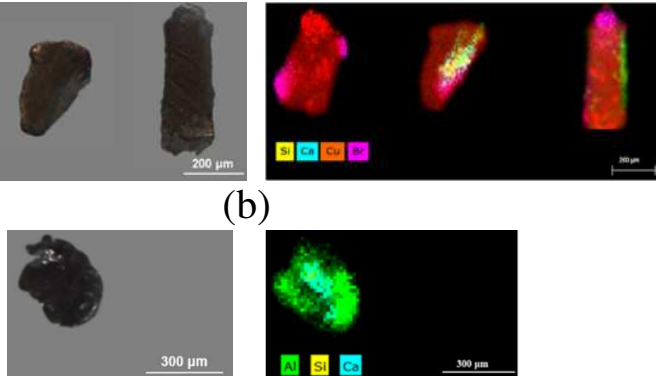

(d)

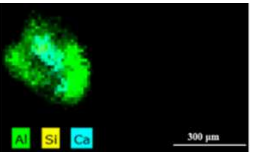

Sample HM2b (0.125-0.350 mm)
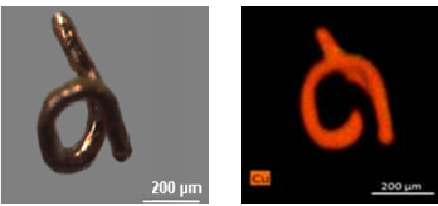

(e)
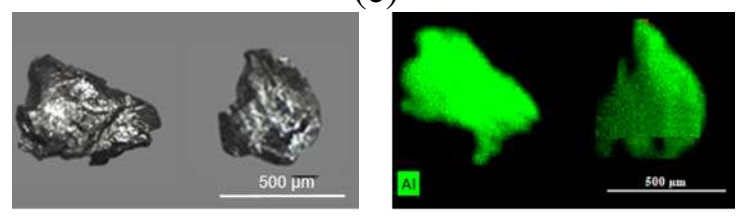

(g)
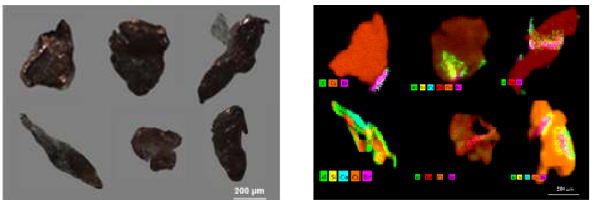

(f)
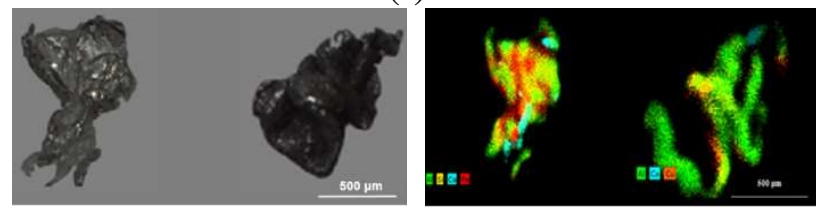

(h)
707

708

709

710

711

712

713

714

715

716

717

718

719

\section{Sample HM2a $(0.350-0.500 \mathrm{~mm})$}

Fig. 4. Sample HM2b (0.125-0.350 mm): (a) unlocked and (b) locked copper particles observed with the stereomicroscope image and with the micro-XRF imaging; (c) unlocked and (d) locked aluminum particles observed with the stereomicroscope image and with the micro-XRF imaging. Sample HM2a (0.350-0.500 mm): (e) unlocked and (f) locked copper particles observed with the stereomicroscope image and with the micro-XRF imaging; (g) unlocked and (h) locked aluminum particles observed with the stereomicroscope image and with the micro-XRF imaging. 


\section{Supplementary materials}

722

723
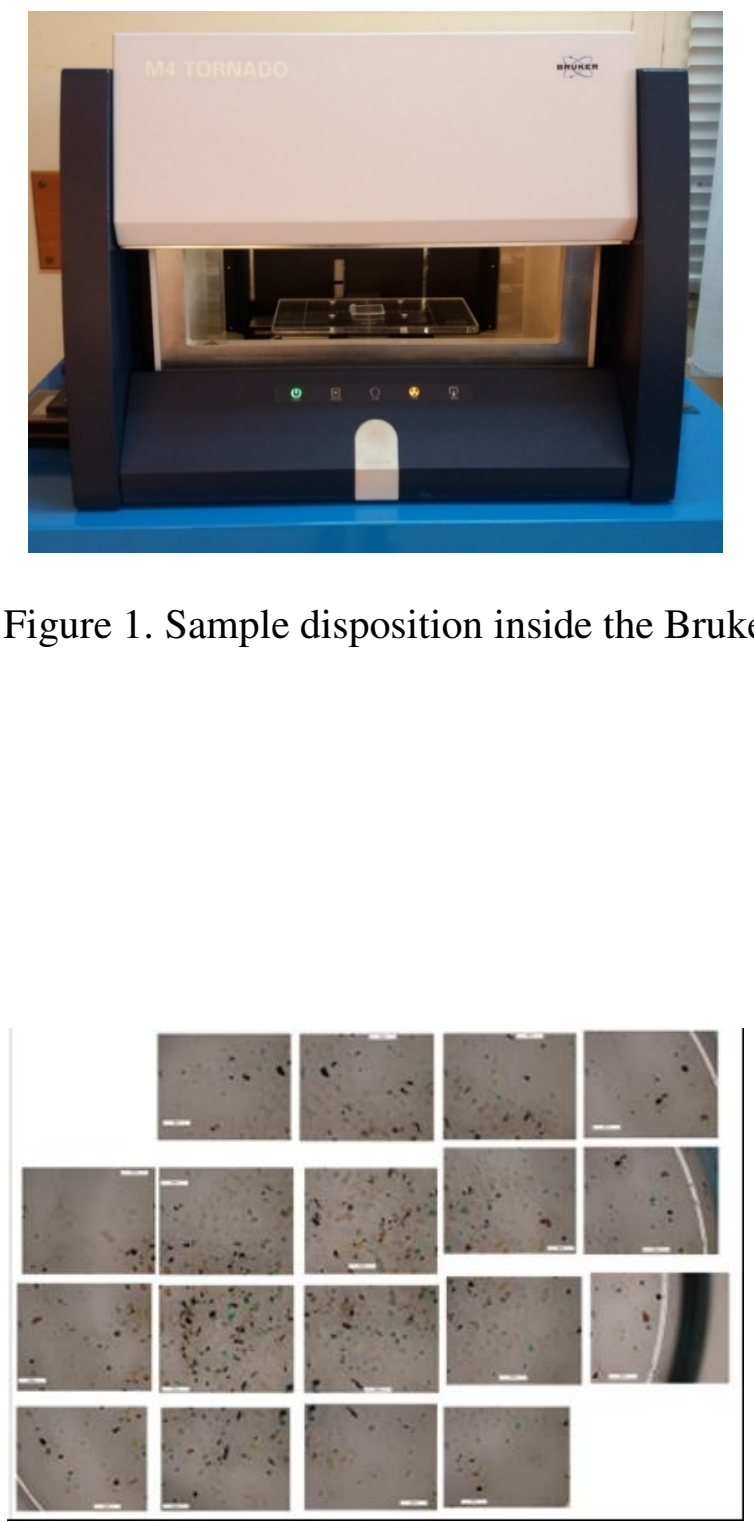

729 Supplementary Figure 2. Optical microscope images combined for further process. Sample HM2b 0.125-0.350 mm. 
735 Supplementary Table 1. Concentrations of the major elements identified by the portable X-Ray

736 Fluorescence (XRF). The analysis is divided by size fractions and for the different hammer 737 mills used (HM1 and HM2). The metal (wt.\%) on the uncrushed PCBs is given at the bottom 738 of the XRF analysis. The 95\% confidence interval and absolute uncertainties for XRF and 739 PGAA respectively are also given next to each metal\% under the symbol of +/- [Adapted 740 from (Otsuki et al., 2019)].

741

742

\begin{tabular}{|l|l|l|l|l|l|l|l|l|l|l|l|}
\hline Mill & Size (mm) & Cu (\%) & $+/-$ & Fe (\%) & $+/-$ & Al (\%) & $+/-$ & Zn (\%) & $+/-$ & Si (\%) & $+/-$ \\
\hline HM1 & $0.35-0.5$ & 11.30 & 1.35 & 0.19 & 0.01 & 3.29 & 0.17 & 0.07 & 0.01 & 3.06 & 0.45 \\
\hline & $0.125-0.35$ & 3.91 & 0.58 & 0.33 & 0.02 & 3.27 & 0.16 & 0.14 & 0.01 & 4.46 & 0.35 \\
\hline HM2 & $0.35-0.5$ & 4.16 & 0.30 & 0.24 & 0.01 & 3.10 & 0.26 & 0.15 & 0.05 & 4.11 & 0.32 \\
\hline & $0.125-0.35$ & 8.25 & 0.56 & 0.27 & 0.02 & 4.46 & 0.34 & 0.34 & 0.07 & 3.77 & 0.13 \\
\hline
\end{tabular}

743

744

745

746

747

748 